DOI: $10.1590 / 1809-6891 v 15 i 327834$

\title{
CRIOPRESERVAÇÃO DO SÊMEN OVINO EM MEIO DILUENTE À BASE DE ÁGUA DE COCO EM PÓ (ACP-102c)
}

\author{
José MaUrício MaCiel CAVALCANTE ${ }^{1}$, OSCAR Oliveira BRASIL ${ }^{2}$, CRISTIANE ClemENTE \\ DE MELlo SAlgueIRO ${ }^{3}$, CARMinda SANDRA BRITO SALMITO-VANDERLEY ${ }^{4}$, JosÉ \\ FERREIRA NUNES ${ }^{4}$ \\ ${ }^{1}$ Professor Doutor da Faculdade Terra Nordeste, Caucaia, CE, Brasil - jmmcavalcante@bol.com.br \\ ${ }^{2}$ Pós-Graduando da Univesidade de Brasília, Brasília, DF, Brasil. \\ ${ }^{3}$ Professora Doutora da Universidade Potiguar e rede RENORBIO, Mossoró, RN, Brasil \\ ${ }^{4}$ Professores Doutores da Universidade Estadual do Ceará, Fortaleza, CE, Brasil
}

\begin{abstract}
O objetivo deste trabalho foi avaliar o diluente ACP-102c na criopreservação do sêmen ovino em comparação com o diluidor tris-glicose-gema (TRIS) e o sêmen fresco. Foram coletados 48 ejaculados de quatro ovinos, sendo tomadas duas alíquotas por ejaculado para diluição e criopreservação em ACP-102c ou TRIS e uma terceira alíquota utilizada para análise do sêmen fresco. O sêmen fresco e o criopreservado em ambos os diluidores foram avaliados para viabilidade, integridade de membrana plasmática e acrossomal, teste hiposmótico, fragmentação do DNA e de motilidade espermática. Após descongelamento, ambos os diluidores não diferiram para viabilidade espermática, integridade de membrana plasmática e acrossomal, fragmentação de DNA e nas
\end{abstract}

variáveis quantitativas e qualitativas de velocidade espermática, mas diferiram no teste hiposmótico, motilidade total e progressiva e amplitude lateral da cabeça, bem como em todas as variáveis de motilidade avaliadas, exceto linearidade e progressividade, após duas horas de incubação à $37{ }^{\circ} \mathrm{C}$. Houve variabilidade entre reprodutores na motilidade total e progressiva do sêmen criopreservado em ACP-102c após descongelamento. O diluidor ACP-102c conferiu menor proteção aos espermatozoides ovinos contra danos do congelamento quando comparado ao TRIS, mas o aprimoramento de sua formulação e protocolos mais adequados de congelação poderão torná-lo uma alternativa na congelação do sêmen ovino.

PALAVRAS-CHAVE: ACP-102c; criopreservação; sêmen ovino.

\section{CRYOPRESERVATION OF RAM SEMEN IN POWDERED COCONUT WATER (ACP-102c) BASED EXTENDER}

\section{ABSTRACT}

The aim of this study was to evaluate the ACP-102c extender in the cryopreservation of ram semen compared to tris-glucose-egg yolk (TRIS) extender and fresh semen. Forty-eight ejaculates were collected from four rams and two aliquots per ejaculate were taken for dilution and cryopreservation in ACP-102c or TRIS and a third aliquot used for the fresh semen analysis. Either the fresh semen and cryopreserved in both extenders were evaluated for viability, integrity of plasma and acrosomal membrane, hypoosmotic swelling test, DNA fragmentation and sperm motility. The extenders did not differ for sperm viability, acrosome and plasma membrane integrity, DNA fragmentation and quantitative and qualitative parameters of sperm velocity after thawing, but differed in hypoosmotic swelling test, total and progressive motility and lateral extent of the head as well as in all motility parameters evaluated (except linearity and straightness) after two hours of incubation at $37{ }^{\circ} \mathrm{C}$. There was variability among rams in total and progressive motility of semen cryopreserved in ACP-102c after thawing. The 
ACP-102c extender showed less protection in the cryopreservation of ram sperm when compared to TRIS, but the improvement in its formulation and freezing

KEYWORDS: ACP-102c; cryopreservation; ram semen.

\section{INTRODUÇÃO}

Diluidores utilizados para preservação seminal contêm ingredientes básicos e aditivos que possibilitam a proteção dos espermatozoides, tais como substratos energéticos, tampões e componentes contra dano criogênico, permitindo a sobrevivência dessas células durante a diluição, o resfriamento e a criopreservação ${ }^{1,2}$. Usualmente, os ingredientes de um diluidor variam desde componentes químicos puros a produtos de origem animal ou vegetal ${ }^{3}$. Dentre os meios diluentes de origem vegetal, destacam-se aqueles à base de água de coco, que têm se mostrado efetivos na conservação de sêmen de caprinos $^{4}, 5$, ovinos ${ }^{6}$, suínos $^{7}$, peixes ${ }^{8}$ e cães ${ }^{9}$.

O diluidor à base de água de coco é de fácil preparo e de baixo custo, mas apresenta limitações como a dificuldade de armazenamento por longos períodos, disponibilidade de frutos (coco) em regiões desprovidas do vegetal e a variabilidade da constituição bioquímica entre frutos, afetando diretamente sua capacidade de preservação ${ }^{10}$ Assim, foi desenvolvido o produto Água de Coco em Pó $\left(\mathrm{ACP}^{\circledR}\right)$, obtido a partir da desidratação da água de coco, e que se caracteriza pela padronização e estabilização sem perdas de suas características bioquímicas, conferindo maior longevidade e estabilidade do produto em relação à água de coco in natura, facilitando seu armazenamento e uso $^{11}$. As características bioquímicas de interesse da $\mathrm{ACP}^{\circledR}$ são similares àquelas encontradas na água de coco, de modo que este diluidor tem sido aprovado para uso na conservação do sêmen de diferentes espécies animais, como ovinos ${ }^{12,}{ }^{13}$, caprinos ${ }^{14}$, suínos ${ }^{15}$, cães ${ }^{10}$, peixes ${ }^{16}$ e espécies silvestres ${ }^{17,18}$.

Apesar dos resultados promissores obtidos com a conservação do sêmen ovino resfriado a $4^{\circ} \mathrm{C}^{12}$, há carência de estudos que demonstrem a viabilidade do uso da água de coco em pó na criopreservação do sêmen ovino. Assim, este trabalho teve como objetivo avaliar a viabilidade, integridade estrutural e funcional de membrana plasmática e acrossomal, fragmentação do DNA e motilidade espermática pós-descongelamento do sêmen ovino criopreservado no diluidor ACP-102c (específico para criopreservação do sêmen desta protocols may make it an alternative to freezing ram semen.

espécie), em comparação com diluidores à base de Tris-glicose-gema (TRIS) e com o sêmen fresco.

\section{MATERIAL E MÉTODOS}

Este trabalho está em conformidade com projeto aprovado pelo Comitê de Ética para o Uso de Animais da Universidade Estadual do Ceará (CEUA-UECE, processo no. 09233050-9) e foi executado no Laboratório de Tecnologia do Sêmen Caprino e Ovino do Núcleo Integrado de Biotecnologia da Universidade Estadual do Ceará, no município de Fortaleza-CE $\left(03^{\circ} 43^{\prime} \mathrm{S}, 38^{\circ} 30^{\prime}\right.$ O). Utilizaram-se quatro reprodutores ovinos da raça Santa Inês, com idade média de três anos, mantidos em baias individuais, alimentados com feno de tifton (Cynodon sp.) e concentrado comercial com $18 \%$ de proteína bruta, além de sal mineral e água à vontade. As colheitas de sêmen foram realizadas com uso de vagina artificial, duas vezes por semana, perfazendo 12 colheitas por animal, totalizando 48 ejaculados. Após a colheita, avaliou-se cada ejaculado quanto ao volume, concentração, motilidade massal, percentual de espermatozoides móveis e vigor ${ }^{19}$. Foram utilizados apenas ejaculados com volume superior a $0,5 \mathrm{~mL}$, concentração mínima de espermatozoides de $3,5 \times 10^{9}$ espermatozoides (sptz)/mL, escore mínimo de 3,5 para motilidade massal e vigor, percentual de espermatozoides móveis superior a $80 \%$ e percentual de anormalidades espermáticas inferior a $10 \%$.

Para a criopreservação utilizaram-se os diluidores ACP-102c e TRIS. O diluidor ACP$102 \mathrm{c}$ foi preparado segundo recomendação do fabricante (ACP Biotecnologia ${ }^{\circledR}$, Fortaleza-Ceará, Brasil). O diluidor TRIS, baseado no proposto por Evans e Maxwell ${ }^{20}$, consistiu na adição de 300 $\mathrm{mM}$ de Tris-(hidroximetil)-aminometano, 94,7 $\mathrm{mM}$ de ácido cítrico monohidratado e $27,8 \mathrm{mM}$ de glicose. Ambos diluidores foram acrescidos de $15 \%$ de gema de ovo e $25 \mathrm{mg}$ de gentamicina para cada $100 \mathrm{~mL}$ de diluidor. Em seguida, os diluidores foram divididos em fração " $A$ " (sem glicerol) e "B" (com adição de $10 \%$ de glicerol) ${ }^{19}$.

As amostras de sêmen de cada ejaculado foram divididas em duas alíquotas e diluídas a 32 ${ }^{\circ} \mathrm{C}$ nas frações "A" de ACP-102c e TRIS até 
concentração de $800 \times 10^{6} \mathrm{sptz} / \mathrm{mL}$. O sêmen diluído foi resfriado até $4{ }^{\circ} \mathrm{C}$ em 120 min., quando adicionou-se da fração "B" de cada diluidor, em três etapas, até concentração final de $400 \times 10^{6}$ $\mathrm{sptz} / \mathrm{mL}$. O sêmen foi envasado em palhetas de $0,25 \mathrm{~mL}$ e mantido em equilíbrio a $4{ }^{\circ} \mathrm{C}$ por duas horas. Após este período de equilíbrio, as palhetas foram colocadas no interior de caixa térmica e congeladas em vapor de nitrogênio líquido ( -80 ${ }^{\circ} \mathrm{C}$ ) por $10 \mathrm{~min}$. , sobre um suporte a $3,5 \mathrm{~cm}$ do nível de nitrogênio e, então, imersas em nitrogênio líquido para armazenamento em botijões criogênicos $\left(-196{ }^{\circ} \mathrm{C}\right)$.

Para avaliação do sêmen criopreservado, uma palheta por diluidor e por cada ejaculado foi descongelada em banho-maria a $37{ }^{\circ} \mathrm{C}$ por 30 segundos e seu conteúdo alocado em minitubos mantidos em banho-maria também a $37{ }^{\circ} \mathrm{C}$, tendo seu conteúdo avaliado ao descongelamento (T0) e após uma (T1) e duas horas (T2) de incubação. Tanto o sêmen fresco como o criopreservado em ACP-102c e em TRIS foram avaliados para viabilidade espermática, integridade acrosomal e de membrana plasmática, teste hiposmótico e fragmentação do DNA espermático logo após descongelamento (T0), e avaliados para motilidade espermática nos momentos $\mathrm{T} 0, \mathrm{~T} 1$ e $\mathrm{T} 2$ de incubação.

Para a viabilidade espermática, utilizou-se a técnica de coloração com eosina-nigrosina ${ }^{19}$, com registro do percentual de espermatozoides vivos não corados (EN).

Para a avaliação simultânea da integridade acrossomal e de membrana plasmática, usou-se a técnica de coloração tripla, com coloração de esfregaços de sêmen em lâminas com os corantes Azul de Tripan, Marrom de Bismark e Rosa Bengala $^{21}$. Duzentos espermatozoides por lâmina foram avaliados em microscopia óptica (100x), sendo classificados em: vivos com acrossoma (VA - região acrossomal rósea e região pós-acrossomal marrom claro), vivos sem acrossoma (VR - região acrossomal e pós-acrossomal marrom claro), mortos com acrossoma (MA - região acrossomal rósea e região pós-acrossomal marrom escuro) e mortos sem acrossoma (MR - região acrossomal e pós-acrossomal marrom escuro).

O teste hiposmótico foi utilizado para avaliação da integridade funcional da membrana espermática, incubando-se $10 \mu \mathrm{L}$ de sêmen fresco ou criopreservado em $100 \mu \mathrm{L}$ de solução hiposmótica $(0,90 \mathrm{~g}$ frutose, $0,49 \mathrm{~g}$ citrato de sódio em $100 \mathrm{~mL}$ de água destilada, $100 \mathrm{mOsm}$ ) a $37{ }^{\circ} \mathrm{C}$ por 60 minutos. Foram contados 200 espermatozoides em microscópio de contraste de fase (1000x) para determinar o percentual daqueles com dobramento de flagelo, tidos como células com membranas funcionalmente intactas reagentes ao meio hiposmótico ${ }^{22}$.

$\mathrm{O}$ percentual de espermatozoides com fragmentação de DNA foi determinado com uso de teste comercial de dispersão da cromatina espermática (SCD, Sperm-Halomax ${ }^{\circledR}$ kit, ChromaCell SL, Madrid, Espanha). Amostras de sêmen fresco ou descongelado foram diluídas a $15 \times 10^{6} \mathrm{sptz} / \mathrm{mL}$ em solução citrato-glicose ${ }^{20}$ para o sêmen fresco, ou em diluidor-base TRIS ou ACP102c (sem gema de ovo ou glicerol) para o sêmen criopreservado, e adicionaram-se $25 \mu \mathrm{L}$ desta diluição a um microtubo contendo agarose de baixo ponto de fusão. Colocou-se uma gota desta suspensão sobre a face de uma lâmina previamente tratada pelo fabricante, coberta com lamínula e resfriada a $4{ }^{\circ} \mathrm{C}$ por $5 \mathrm{~min}$. Após a remoção cuidadosa da lamínula, a lâmina foi colocada horizontalmente em $10 \mathrm{~mL}$ de solução de lise por 5 min., em temperatura ambiente, sendo posteriormente imersa em água destilada (5 min.) para remoção desta solução de lise e desidratada por imersão sequencial em soluções de 70,90 e $100 \%$ de etanol ( 2 min. cada) e secas ao ar. As lâminas foram coradas com solução de Wright em tampão de fosfato (1:1) durante 5-10 min., lavadas em água destilada e secas ao ar para serem analisadas em microscópio óptico (400x). Quinhentos espermatozoides foram avaliados e o percentual de células com DNA fragmentado (DNAf) determinado pela presença de grande halo de dispersão de cromatina ao redor da cabeça do espermatozoide.

A motilidade espermática foi avaliada em sistema de análise de sêmen auxiliado por computador (CASA), com uso do programa Sperm Class Analyser ${ }^{\circledR}\left(\mathrm{SCA}^{\circledR}\right.$, Microptic S.L, Barcelona, Espanha) que processa imagens obtidas em microscópio de contraste de fase acoplado a uma câmara digital. Foram utilizadas as seguintes variáveis do programa: 25 quadros/s, sendo 25 quadros/campo, velocidade limite para espermatozoides lentos de $30 \mu \mathrm{m} / \mathrm{s}$, limite para velocidade média de $60 \mu \mathrm{m} / \mathrm{s}$, retilinearidade mínima para espermatozoides progressivos de $80 \%$. Para a avaliação, diluiu-se o sêmen fresco ou descongelado em solução citrato-glicose ${ }^{20}$ a $37^{\circ} \mathrm{C}$, até a concentração de $40 \times 10^{6} \mathrm{sptz} / \mathrm{mL}$. Dez microlitros desta diluição foram colocados em 
câmara de Makler (Sefi Medical Instruments Ltda, Haifa, Israel), pré-aquecida a $37{ }^{\circ} \mathrm{C}$, para se estudar as variáveis: percentual de espermatozoides móveis totais (MOV), percentual de espermatozoides com movimento progressivo (PROG), velocidade curvilinear (VCL $-\mu \mathrm{m} / \mathrm{s}$ ), velocidade média do percurso (VAP - $\mu \mathrm{m} / \mathrm{s}$ ), linearidade (LIN - \%), progressividade (STR - \%), deslocamento lateral de cabeça (ALH - $\mu \mathrm{m})$ e frequência de batimento cruzado (BCF - $\mathrm{Hz}$ ). Além disso, visando avaliar possível efeito individual na criopreservação de sêmen dos reprodutores utilizados, os resultados da variável MOV foram reunidos para cada reprodutor e utilizados na determinação de sua congelabilidade seminal nos diluidores ACP-102c e TRIS, definida como relação percentual da variável MOV do sêmen criopreservado num diluidor ao descongelamento (momento T0) em relação à motilidade total no sêmen fresco do mesmo ejaculado (Congelabilidade $=\mathrm{MOV}$ ao descongelamento/MOV sêmen fresco * 100).

Os resultados foram expressos em termos de média \pm erro padrão. Após transformação em arcoseno dos valores em percentual, as médias foram comparadas usando-se análise de variância (ANOVA), seguido de teste de Tukey com nível de significância de 5\% para determinar diferenças significativas entre sêmen fresco e criopreservado nos diluidores ACP-102c e TRIS nas variáveis de qualidade seminal avaliadas. Os resultados para a congelabilidade do sêmen em ACP-102c ou TRIS dos diferentes reprodutores utilizados também foram transformados a arcoseno e submetidos à ANOVA, seguido de teste de Tukey com nível de significância de 5\% para determinar diferenças na congelabilidade seminal entre reprodutores em cada diluidor avaliado. Todos os procedimentos estatísticos foram realizados no programa SYSTAT 12 for Windows ${ }^{\circledR}$ (SYSTAT Software Inc.).

\section{RESULTADOS E DISCUSSÃO}

Os resultados para viabilidade, integridade de membrana acrossomal e plasmática, teste hiposmótico e percentual de células espermáticas com fragmentação de seu DNA estão apresentados na Tabela 1. A criopreservação afetou significativamente $(\mathrm{P}<0,05) \quad \mathrm{o}$ percentual de viabilidade espermática avaliado pelo método de coloração por eosina-nigrosina (EN), com redução deste percentual no sêmen criopreservado (em ACP-102c ou TRIS) quando comparado ao fresco. De modo semelhante, a criopreservação afetou as variáveis avaliadas pela técnica de coloração tripla, com redução no percentual de espermatozoides vivos com acrossoma intacto (VA) e aumento no percentual de espermatozoides mortos com ou sem acrossoma (MA e MR, respectivamente) no sêmen criopreservado, nos dois diluidores testados em comparação ao fresco $(\mathrm{P}<0,05)$. Apenas o percentual de espermatozoides vivos sem acrossoma (VR) não foi alterado pela criopreservação $(\mathrm{P}>0,05)$. A criopreservação também reduziu $(\mathrm{P}<0,05)$ o percentual de espermatozoides reativos ao teste hiposmótico (HOST) nos diluidores seminais utilizados quando comparados ao sêmen fresco.

Tabela 1. Valores percentuais (média \pm erro padrão) das variáveis de viabilidade espermática avaliadas pelas técnicas de coloração com eosina-nigrosina (EN), coloração tripla (VA, VR, MA e MR), teste hiposmótico (HOST) e de espermatozoides com DNA fragmentado (DNAf) no sêmen ovino fresco e criopreservado em TRIS e ACP- 102c

\begin{tabular}{lccc}
\hline \multirow{2}{*}{ Variável } & \multirow{2}{*}{ Sêmen fresco } & \multicolumn{2}{c}{ Sêmen criopreservado } \\
\cline { 3 - 4 } & & TRIS & ACP-102c \\
\hline EN (\%) & $86,5 \pm 1,2^{\mathrm{a}}$ & $51,9 \pm 2,0^{\mathrm{b}}$ & $50,0 \pm 1,7^{\mathrm{b}}$ \\
VA (\%) & $88,6 \pm 1,4^{\mathrm{a}}$ & $50,9 \pm 1,8^{\mathrm{b}}$ & $48,3 \pm 1,8^{\mathrm{b}}$ \\
VR (\%) & $1,2 \pm 0,2$ & $1,7 \pm 0,3$ & $1,8 \pm 0,3$ \\
MA (\%) & $7,7 \pm 1,2^{\mathrm{b}}$ & $20,4 \pm 1,5^{\mathrm{a}}$ & $19,6 \pm 1,6^{\mathrm{a}}$ \\
MR (\%) & $2,4 \pm 0,4^{\mathrm{b}}$ & $26,5 \pm 1,7^{\mathrm{a}}$ & $30,3 \pm 2,2^{\mathrm{a}}$ \\
HOST (\%) & $61,9 \pm 3,0^{\mathrm{a}}$ & $40,4 \pm 3,6^{\mathrm{b}}$ & $25,6 \pm 2,2^{\mathrm{c}}$ \\
DNAf $(\%)$ & $1,7 \pm 0,2$ & $1,4 \pm 0,6$ & $1,8 \pm 1,1$ \\
\hline
\end{tabular}

Letras diferentes na mesma linha indicam diferenças estatísticas $(\mathrm{P}<0,05)$.

$\mathrm{VA}=$ espermatozoides vivos com acrossoma; $\mathrm{VR}=$ espermatozoides vivos sem acrossoma; $\mathrm{MA}=$ espermatozoides mortos com acrossoma; $\mathrm{MR}=$ espermatozoides mortos sem acrossoma. 
A integridade das membranas acrossomal e plasmática são atributos essenciais para a fertilidade do espermatozoide ${ }^{23,24}$. É conhecida a ação da criopreservação em induzir danos ultraestruturais na membrana plasmática e acrossomal, bem como na região do flagelo, com decréscimo da integridade funcional e da sobrevivência espermática ${ }^{1}$. Neste estudo, a criopreservação também afetou o percentual de espermatozoides com integridade estrutural e funcional de membrana para ambos os diluidores.

$\mathrm{Na}$ comparação entre os diluidores, não foram encontradas diferenças $(\mathrm{P}>0,05)$ no sêmen criopreservado em ACP-102c ou TRIS para as variáveis avaliadas pelas técnicas de coloração empregadas. Porém, o percentual de células reagentes ao teste hiposmótico foi afetado pelo tipo de diluidor $(\mathrm{P}<0,05)$, com menores valores para o sêmen criopreservado em ACP-102c (Tabela 1). O teste hiposmótico avalia a integridade funcional da membrana espermática em sua reatividade ao ambiente hiposmótico, enquanto que os testes com corantes vitais permitem estudar a integridade estrutural da membrana espermática baseada na permeabilidade da membrana ao corante vital, sendo possível a ocorrência de espermatozoides vivos com membranas estruturalmente íntegras, mas não funcionais $^{23}$. O fato dos diluidores ACP-102c e TRIS diferirem no teste hiposmótico, mas não nas variáveis avaliadas pelos métodos de coloração utilizados, pode indicar que ambos os diluidores protegem diferentemente a célula espermática na criopreservação, sendo equivalentes na preservação da integridade estrutural de membrana acrossomal e plasmática, mas diferindo quanto à proteção de sua funcionalidade.

No percentual de células espermáticas com fragmentação de seu DNA também não foram encontradas diferenças significativas $(\mathrm{P}>0,05)$ entre o sêmen fresco ou criopreservado em ACP-102c ou TRIS, indicando não ter ocorrido efeito da criopreservação ou do tipo de diluidor utilizado sobre a integridade da cromatina espermática logo após descongelamento (T0). Esses resultados são similares aos encontrados por outros autores ${ }^{25}, 26$. Ainda que a criopreservação provoque danos na cromatina do espermatozoide, a suscetibilidade do DNA espermático à criopreservação nem sempre é evidente no início da incubação, sendo observável após longas horas (>4-5h) quando, então, a motilidade espermática encontra-se bastante reduzida $^{26,27}$. Neste trabalho, optou-se por avaliar a variável DNAf no sêmen fresco e após descongelamento (T0), visando avaliar efeitos agudos da criopreservação na integridade do DNA espermático. Apesar de não ter sido verificado efeito da criopreservação na integridade do DNA espermático, a possibilidade de ocorrência de danos latentes não deve ser excluída.

Os efeitos da criopreservação também foram observados nas variáveis de motilidade avaliadas em sistema CASA. Excetuando-se as variáveis velocidade média do percurso (VAP) e linearidade (LIN), em todos as demais foi possível verificar a superioridade $(\mathrm{P}<0,05)$ do sêmen fresco em comparação ao criopreservado (Tabela 2).

Tabela 2. Média \pm erro padrão das variáveis de motilidade do sêmen ovino fresco e criopreservado em TRIS e ACP-102c, avaliados no sistema CASA

\begin{tabular}{lccc}
\hline \multirow{2}{*}{ Variável } & \multirow{2}{*}{ Sêmen fresco } & \multicolumn{2}{c}{ Sêmen criopreservado } \\
\cline { 3 - 4 } & & TRIS & ACP-102c \\
\hline MOV $(\%)$ & $78,7 \pm 1,5^{\mathrm{a}}$ & $63,1 \pm 2,6^{\mathrm{b}}$ & $39,0 \pm 2,8^{\mathrm{c}}$ \\
PROG $(\%)$ & $46,7 \pm 1,4^{\mathrm{a}}$ & $32,3 \pm 1,4^{\mathrm{b}}$ & $19,7 \pm 1,5^{\mathrm{b}}$ \\
VCL $(\mu \mathrm{m} / \mathrm{s})$ & $131,9 \pm 2,6^{\mathrm{a}}$ & $123,3 \pm 2,0^{\mathrm{b}}$ & $116,1 \pm 2,1^{\mathrm{b}}$ \\
VAP $(\mu \mathrm{m} / \mathrm{s})$ & $108,3 \pm 3,2^{\mathrm{a}}$ & $104,9 \pm 2,0^{\mathrm{a}}$ & $101,7 \pm 2,3^{\mathrm{a}}$ \\
LIN $(\%)$ & $66,8 \pm 1,2^{\mathrm{a}}$ & $67,4 \pm 1,0^{\mathrm{a}}$ & $68,9 \pm 1,4^{\mathrm{a}}$ \\
STR $(\%)$ & $82,0 \pm 0,7^{\mathrm{a}}$ & $79,2 \pm 0,7^{\mathrm{b}}$ & $78,6 \pm 1,1^{\mathrm{b}}$ \\
ALH $(\mu \mathrm{m})$ & $3,4 \pm 0,1^{\mathrm{a}}$ & $3,0 \pm 0,1^{\mathrm{b}}$ & $2,6 \pm 0,1^{\mathrm{c}}$ \\
BCF $(\mathrm{Hz})$ & $9,4 \pm 0,2^{\mathrm{a}}$ & $8,1 \pm 0,1^{\mathrm{b}}$ & $7,9 \pm 0,1^{\mathrm{b}}$ \\
\hline
\end{tabular}

Letras diferentes na mesma linha indicam diferenças estatísticas $(\mathrm{P}<0,05)$.

MOV = percentual de espermatozoides móveis totais; $\mathrm{PROG}=$ percentual de espermatozoides com movimento progressivo; $\mathrm{VCL}=$ velocidade curvilinear; VAP = velocidade média do percurso; LIN = linearidade; STR = retilinearidade; ALH = amplitude lateral da cabeça do espermatozoide; $\mathrm{BCF}=$ frequência de batimento cruzado.

Os efeitos da incubação do sêmen criopreservado em ACP-102c e TRIS nos momentos T0, T1 e T2 nas variáveis de motilidade avaliadas em sistema CASA estão apresentados na Figura 1 (a-h). Redução significativa $(\mathrm{P}<0,05)$ foi observada para ambos os diluidores nas variáveis de MOV, PROG, 
VCL, VAP e LIN ao final de duas horas de incubação (Figura 1 a-e). Redução nas variáveis STR e BCF e aumento em ALH $(\mathrm{P}<0,05)$ no momento T2 em relação a T0 foram observadas com o diluidor TRIS, mas não para ACP-102c (Figura $1 \mathrm{f}-\mathrm{h}$ ).

Ao final de duas horas de incubação, foram encontradas diferenças $(\mathrm{P}<0,05)$ entre os diluidores
ACP-102c e TRIS para todas as variáveis de motilidade, exceto LIN e STR (Figura 1 e-f). A diferença entre diluidores para as variáveis MOV e PROG, verificadas logo após descongelamento, foi mantida praticamente constante durante incubação (Figura $1 \mathrm{a}-\mathrm{b}$ ).

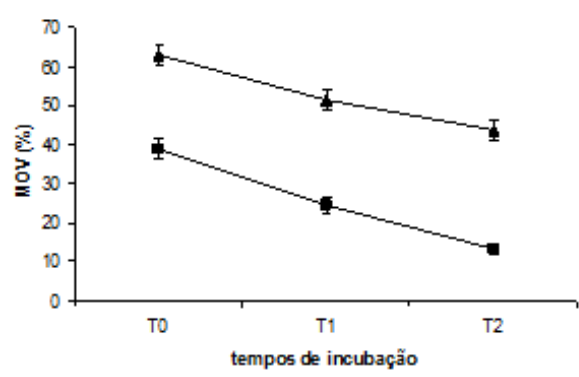

(a)

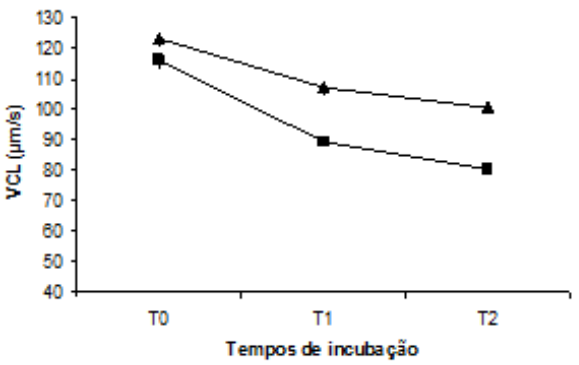

(c)
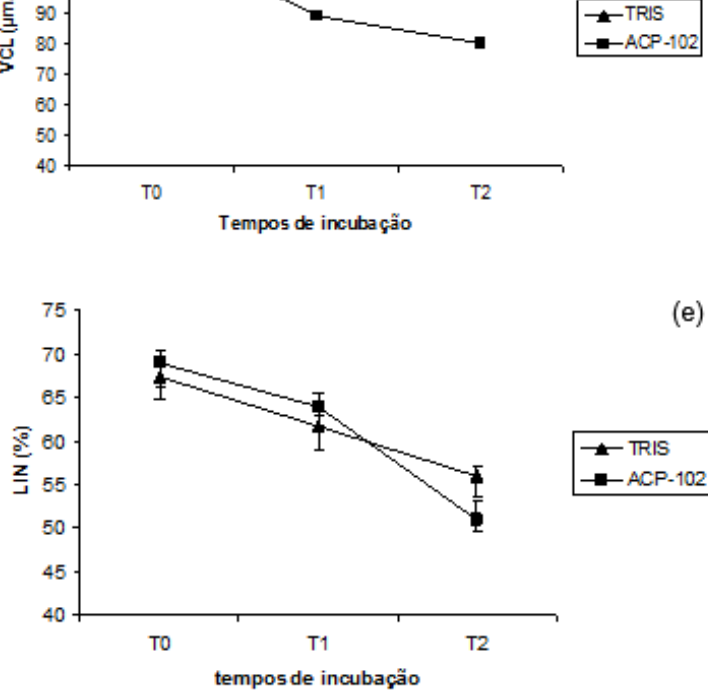

(e)

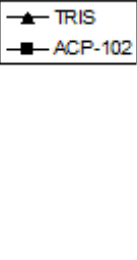

(g)

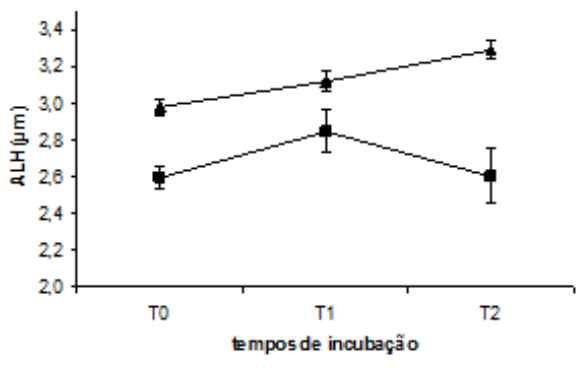

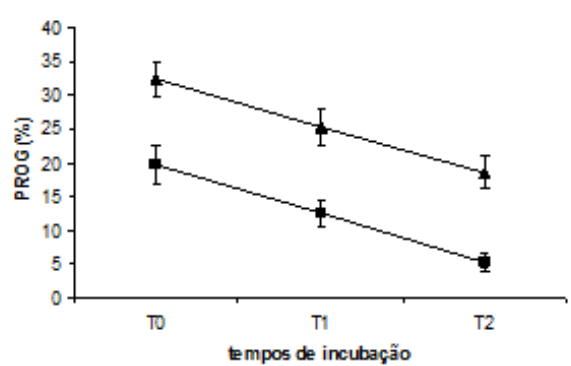

(b)

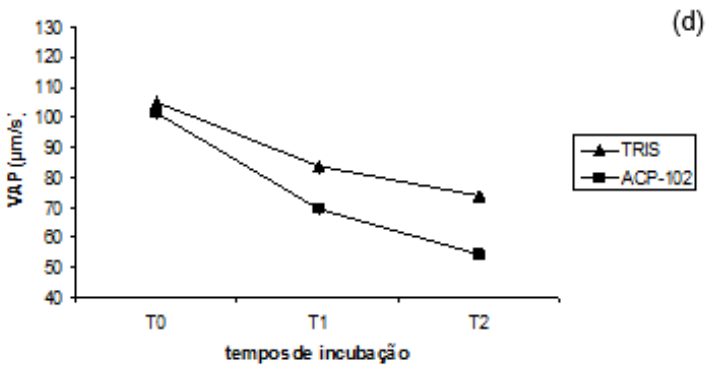

(f)

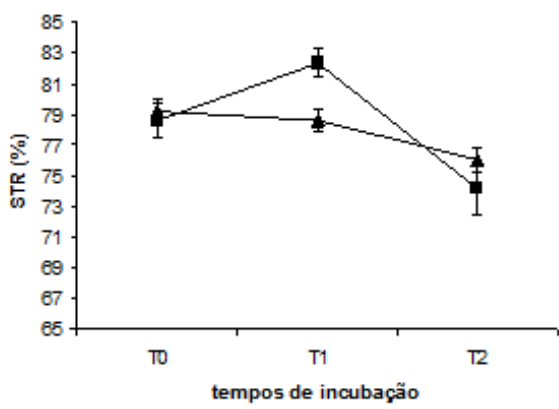

(h)

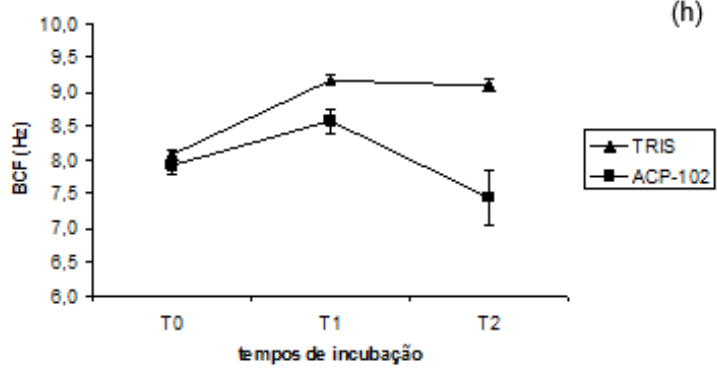

Figura 1. Variáveis de motilidade de sêmen ovino criopreservado em ACP-102c e TRIS avaliadas em sistema CASA ao descongelamento (T0), após uma (T1) e duas horas (T2) de incubação a $37^{\circ} \mathrm{C}:($ a) $\mathrm{MOV}=$ percentual de espermatozoides móveis totais; (b) PROG = percentual de espermatozoides com movimento progressivo; (c) VCL = velocidade curvilinear; (d) VAP = velocidade média do percurso; (e) LIN = linearidade; (f) STR = retilinearidade; (g) ALH = amplitude lateral da cabeça do espermatozoide; (h) BCF = frequência de batimento cruzado. 
A redução verificada na quase totalidade das variáveis de motilidade avaliadas no sistema CASA entre o sêmen fresco e o criopreservado (Tabela 2) acompanhou a diminuição do percentual de células viáveis encontradas tanto pelo método de coloração por eosina-nigrosina e coloração tripla, como no teste hiposmótico (Tabela 1), e é atribuída ao congelamento. Células espermáticas que sobrevivem ao processo de congelamento-descongelamento apresentam alterações induzidas pela criopreservação (particularmente na membrana plasmática), resultando numa população de espermatozoides com menor tempo de vida ${ }^{28}$. Alterações ultraestruturais, bioquímicas e funcionais ocorridas durante o processo de criopreservação levam à redução da motilidade e perda de viabilidade espermática ${ }^{1}$. Como verificado neste trabalho, tanto o percentual avaliado de células viáveis pelas técnicas de coloração e pelo HOST, como as variáveis de motilidade estudadas pelo sistema CASA foram reduzidos após criopreservação.

Logo após o descongelamento, o sêmen criopreservado nos diluidores TRIS e ACP-102c diferiu estatisticamente $(\mathrm{P}<0,05)$ para as variáveis MOV, PROG e ALH, o que não ocorreu para as demais variáveis $(\mathrm{P}>0,05)$ (Tabela 2). Os diluidores ACP-102c e TRIS apresentaram similar preservação quantitativa (VCL, VAP) e qualitativa (STR e LIN) da velocidade dos espermatozoides; no entanto, após duas horas de incubação do sêmen a $37{ }^{\circ} \mathrm{C}$, o diluidor ACP-102c diferiu do diluidor TRIS nas demais variáveis de motilidade $(\mathrm{P}<0,05)$, exceto para LIN (Figura 1). A variável LIN está associada com o padrão de movimento linear da célula espermática (29), de modo que a semelhança estatística entre ACP-102c e TRIS para esta variável indica que ambos diluidores mantêm semelhante padrão de movimento espermático após duas horas de incubação.

O dano mitocondrial durante a criopreservação pode ser a maior razão para redução da qualidade do sêmen pós-descongelamento ${ }^{30}$. Além disso, as variáveis de velocidade são consideradas indicadores indiretos da função mitocondrial do espermatozoide ${ }^{31}$. É razoável supor que a redução em MOV e PROG encontrada para o diluidor ACP-102c deva-se à menor proteção deste diluidor às injúrias sofridas nas mitocôndrias dos espermatozoides no criodano. Porém, uma vez que as variáveis de velocidade obtidas com ambos os diluidores, logo após descongelamento, foram estatisticamente semelhantes, é possível que a atividade mitocondrial após descongelamento nos espermatozoides móveis (e, por isso, com algum grau de integridade mitocondrial) criopreservados em ACP-102c, estivesse compatível com aquela encontrada nos espermatozoides criopreservados em TRIS.

A eficiência do diluidor $\mathrm{ACP}^{\circledR}$ na conservação do sêmen ovino resfriado, tanto em avaliações in vitro, como resultantes de inseminação artificial, tem sido relatada. Braz et al. ${ }^{32}$ não verificaram diferenças estatísticas para a qualidade do sêmen ovino resfriado a $4{ }^{\circ} \mathrm{C}$ ou $15{ }^{\circ} \mathrm{C}$ por $2 \mathrm{~h}$ em diluidores ACP-102 ou leite. Figueirêdo et al. ${ }^{12}$ encontraram percentual de $72,28 \%$ de ovelhas prenhes inseminadas com sêmen ovino diluído em ACP-102 e resfriado a $4{ }^{\circ} \mathrm{C}$ por $24 \mathrm{~h}$. Machado et al. ${ }^{13}$, com uso de sêmen resfriado a $4{ }^{\circ} \mathrm{C}$ diluído em ACP-102, obtiveram fertilidade de 48,0\% nas ovelhas inseminadas por via cervical e de 70,3\% para inseminadas por laparoscopia. Esses trabalhos apontam para a aplicabilidade do diluidor ACP-102 na conservação do sêmen ovino.

A semelhança estatística entre os diluidores ACP-102c e TRIS quanto aos resultados obtidos de viabilidade pelas técnicas de coloração por eosinanigrosina e coloração tripla, nas variáveis qualitativas (STR e LIN) e quantitativas (VCL e VAP) de velocidade logo após descongelamento e da variável LIN após duas horas de incubação, podem ser sugestivos da possibilidade do uso do ACP-102c na conservação do sêmen ovino criopreservado. Sabe-se que a taxa ótima de resfriamento, congelamento e descongelamento pode diferir com a composição do diluidor ${ }^{2} \mathrm{e}$, no presente estudo, o protocolo de criopreservação em ACP-102c foi o mesmo adotado para a criopreservação em TRIS. É possível postular que o procedimento de criopreservação adotado ainda não seja o protocolo ótimo para o diluidor ACP-102c de modo que novos procedimentos de criopreservação poderiam ser testados.

A congelabilidade do sêmen ovino criopreservado em TRIS e ACP-102c foi comparada entre os reprodutores utilizados (Tabela 3). Apesar de não terem sido encontradas diferenças entre reprodutores para congelabilidade em TRIS $(\mathrm{P}>0,05)$, o sêmen criopreservado em ACP-102c apresentou variabilidade individual e o Reprodutor 3 mostrou melhor congelabilidade em relação aos demais, indicando possível influência individual na congelabilidade do sêmen neste diluidor.

A melhor congelabilidade na criopreservação em ACP-102c do sêmen do Reprodutor 3 em relação aos demais possivelmente seja devida a uma interação entre o diluidor $\mathrm{e}$ as características seminais individuais do referido animal. É conhecido o fato de ocorrerem variações individuais entre animais ou mesmo entre ejaculados de um mesmo 
animal $^{3,} 33,34$. Essa variabilidade individual pode ocorrer na composição proteica do plasma seminal entre animais ${ }^{35,} 36$. Um importante papel tem sido atribuído aos componentes proteicos do plasma seminal na manutenção da motilidade espermática ${ }^{35}$, ${ }^{37}$, na melhoria da viabilidade ${ }^{38,39}$ e na proteção da membrana plasmática ao choque térmico ${ }^{40,41}$. A variabilidade na composição seminal pode explicar os diferentes graus de suscetibilidade do sêmen entre animais. Além disso, componentes do plasma seminal interagem com constituintes dos diluidores ${ }^{42}$. Portanto, é possível a ocorrência de interações entre os constituintes do plasma seminal e da composição da membrana plasmática destes espermatozoides com os componentes do diluidor ACP-102c durante o processo de criopreservação.

Tabela 3. Média \pm erro padrão da congelabilidade (\%) do sêmen ovino criopreservado nos diluidores TRIS e ACP-102c, segundo os reprodutores utilizados

\begin{tabular}{lcccc}
\hline Diluidor & Reprodutor 1 & Reprodutor 2 & Reprodutor 3 & Reprodutor 4 \\
\hline TRIS & $86,4 \pm 4,2^{\mathrm{a}}$ & $70,2 \pm 6,0^{\mathrm{a}}$ & $75,9 \pm 5,4^{\mathrm{a}}$ & $77,9 \pm 7,5^{\mathrm{a}}$ \\
ACP-102c & $59,5 \pm 7,6^{\mathrm{b}}$ & $57,3 \pm 7,6^{\mathrm{b}}$ & $84,0 \pm 6,9^{\mathrm{a}}$ & $53,0 \pm 6,9^{\mathrm{b}}$ \\
\hline
\end{tabular}

Letras minúsculas diferentes na mesma linha diferem estatisticamente $(\mathrm{P}<0,05)$

\section{CONCLUSÕES}

O diluente à base de água de coco em pó (ACP-102c) conferiu menor proteção na congelação de espermatozoides ovinos avaliados in vitro em comparação ao diluente TRIS. Entretanto, a semelhança de ambos diluidores na viabilidade, integridade de membrana plasmática e acrossomal, integridade do DNA espermático e das variáveis de velocidade dos espermatozoides logo após o descongelamento sugere a potencialidade do ACP102 c como alternativa para a congelação do sêmen ovino, sendo possível melhorar sua capacidade de preservação dos espermatozoides ao criodano por meio do aprimoramento de sua formulação, estudo da interação diluente-espermatozoide e melhor adequação do protocolo de congelação.

\section{AGRADECIMENTOS}

À Fundação Cearense de Apoio ao Desenvolvimento Científico e Tecnológico (FUNCAP) pelo financiamento da pesquisa.

\section{REFERÊNCIAS}

1. Salamon S, Maxwell WMC. Storage of ram semen. Anim Reprod Sci. 2000;62:77-111.

2. Salamon S, Maxwell, WMC. Frozen storage of ram semen. I. Procesing, freezing, thawing and fertility after cervical insemination. Anim Reprod Sci. 1995;37:185249.

3. Gil J, Rodriguez-Irazoqui M, Lundeheim N, Soderquist L, Rodriguez-Martinez H. Fertility of ram semen frozen in Bioexcell and used for cervical artificial insemination. Theriogenology. 2003;59: 1157-1170.

4. Nunes JF. A inseminação artificial em caprinos no
Nordeste do Brasil. Rev Bras Reprod Anim. 1988;12:8591.

5. Campos ACN, Nunes JF, Monteiro AWU, Pinheiro JHT, Ferreira MAL, Araujo AA, Cruz JF. Conservação do sêmen caprino a $4^{\circ} \mathrm{C}$ durante o período seco e chuvoso no Nordeste do Brasil. Rev Bras Reprod Anim. 2003;27:620624.

6. Figueiredo EL, Monteiro AWU, Silva Filho AHS, Campos ACN, Nunes JF. Avaliação in vitro do sêmen ovino resfriado diluído em água de coco previamente criopreservado em nitrogênio líquido. Rev Bras Reprod Anim. 2001;25:430-431.

7. Toniolli R, Mesquita DSM, Cavalcante SG. Avaliação in vitro do sêmen suíno diluído em BTS e na água de coco in natura e estabilizada. Rev Bras Reprod Anim. 1998;22:198-201.

8. Carvalho MAM, Nunes JF, Gondim JM. Prolongamento da motilidade de espermatozoides de carpa comum, Cyprinus carpio L., pelo uso de água de coco (Cocos nucifera) como diluidor de sêmen. Rev Bras Reprod Anim. 2002;5:184-186.

9. Cardoso RCS, Silva AR, Uchoa DC, Silva LDM. Cryopreservation of canine semen using a coconut water extender with egg yolk and three different glycerol concentrations. Theriogenology. 2003;59: 743-751.

10. Cardoso RCS, Silva AR, Silva LDM. Use of the powdered coconut water (ACP-106) for cryopreservation of canine spermatozoa. Anim Reprod. 2005;2:257-262.

11. Nunes JF, Salgueiro CCM. Strategies to improve the reproductive efficiency of goats in Brazil. Small Rumin Res. 2011;98:176-184.

12. Figueirêdo EL, Nunes JF, Cordeiro MA, Souza PT, Diógenes Filho RN, Vieira VE, Silva Filho AHS, Mesquita FLT, Salgueiro CCM, Feitosa, JV. Inseminação artificial de ovelhas da raça Santa Inês com sêmen diluído em água de coco in natura e em pó. $\mathrm{R}$ Bras Ci Vet. 2007; 14:95-97. 
13. Machado VP, Nunes JF, Araújo AA, Fernandez DRP, Cordeiro MA, Medeiros CHN, Medeiros ALN, Monteiro AWU. Fertilidade após inseminação artificial intracervical ou laparoscópica intra-uterina de ovelhas utilizando diluidores à base de água de coco. Braz J Vet Res Anim Sci. 2006;43: 43-49.

14. Oliveira RV, Nunes JF, Salgueiro CCM, Cavalcante JMM, Brasil OO, Moura AAA. Avaliação de espermatozoides caprinos congelados em meio à base de água de coco em pó (ACP-101) ou TRIS. Arq Bras Med Vet Zootec. 2011;6:1295-1302.

15. Toniolli R, Toniollo GH, Francesquini PH, Morato FMAC. Uso do diluente água de coco em pó (ACP-103) na conservação prolongada do sêmen do varrão: avaliação in vitro $\mathrm{e}$ in vivo. Arq. Bras. Med. Vet. Zootec. 2010;62:1072-1079.

16. Viveiros ATM, Nascimento AF, Orfao LH, Isau ZA. Motility and fertility of the subtropical freshwater fish streaked prochilod (Prochilodus lineatus) sperm cryopreserved in powdered coconut water. Theriogenology. 2010; 74:551-556.

17. Silva MA, Peixoto GCX, Santos EAA, Castelo TS Oliveira MF, Silva AR. Recovery and cryopreservation of epididymal sperm from agouti (Dasiprocta aguti) using powdered coconut water $(\mathrm{ACP}-109 \mathrm{c})$ and Tris extenders. Theriogenology. 2011;76:1084-1089.

18. Silva MA, Peixoto GC, Lima GL, Bezerra JA, Campos LB, Paiva AL, Paula VV, Silva AR. Cryopreservation of collared peccaries (Tayassu tajacu) semen using a powdered coconut water (ACP-116c) based extender plus various concentrations of egg yolk and glycerol. Theriogenology. 2012;78:605-611.

19. Chemineau P, Cagnie Y, Guerin Y, Orgeur P, Vallet JC. Training Manual on Artificial Insemination in Sheep and Goats. Rome: Food and Agriculture Organization of the United Nations; 1991. 223p.

20. Evans G, Maxwell WMC. Inseminación artificial de ovejas y cabras. 1st ed. Zaragoza: Acribia; 1990. 192p. Spanish.

21. Garde JJ, Perez-Guzman MD, Perez SS, Montoro V. Ionophore-induced acrosome reaction in ram spermatozoa: A possible test in the diagnosis of male subfertility. Arch Zootec. 1997;46:43-49.

22. Bucak MN, Tuncer PB, Sariözkan S, Ulutas PB. Comparison of the effects of glutamine and an amino acid solution on post-thawed ram sperm parameters, lipid peroxidation and anti-oxidant activities. Small Rum Res. 2009;81:13-17.

23. Jeyendran RS, Van Der Ven HH, Perez-Pelaez M, Crabo BG, Zaneveld LJD. Development of an assay to assess the functional integrity of the human sperm membrane and its relationship to other semen characteristics. J Reprod Fert. 1984;70:219-228.

24. Watson P. Recent developments and concepts in the cryopreservation of spermatozoa and the assessment of their post-thawing function. Reprod Fert Develop. 1995;7:871-891.

25. Gosálvez J, Vázquez JM, Enciso M, Fernández JL, Gosálbez A, Bridle JJ, López-Fernández C. Sperm DNA Fragmentation in Rams Vaccinated with Miloxan. Open Vet Sci J. 2008;2:7-10.

26. Lopez-Fernandez C, Fernandez JL, Gosalbez A, Arroyo F, Vazquez JM, Holt WV, Gosalvez J. Dynamics of sperm DNA fragmentation in domestic animals III. Ram. Theriogenology. 2008;70:898-908.

27. López-Fernández C, Johnston SD, Gosálbez A, Gosálvez J. Seasonal changes in sperm DNA fragmentation of Murciano-Granadina goats: The compelling case for dynamic assessment. Small Rum Res. 2011;100:50-53.

28. Pérez LJ, Valcárcel A, de las Heras MA, Moses D, Baldassarre $H$. Evidence that frozen/thawed ram spermatozoa show accelerated capacitation in vitro as assessed by chlortetracycline assay. Theriogenology. 1996;46:131-140.

29. Mortimer ST. A critical review of the physiological importance and analysis of sperm movement in mammals. Hum Reprod Update. 1997;3:403-439.

30. Schober D, Aurich C, Nohl H, Gille L, Influence of cryopreservation on mitochondrial functions in equine spermatozoa. Theriogenology. 2007;68:745-754.

31. Budworth PR, Amann RP, Chapman PL. Relationships between computerized measurements of frozen and thawed bull spermatozoa and fertility. J Androl. 1988;9:41-54.

32. Braz VB, Araújo AA, Nunes JF, Machado VP, Moura AAAN, Oliveira KPL. Viabilidade do sêmen ovino diluído em água de coco em pó. Rev Bras Reprod Anim. 2003;27:328-329.

33. Söderquist L, Madrid-Bury N, Rodriguez-Martinez H. Assessment of ram sperm membrane integrity following different thawing procedures. Theriogenology. 1997;48:115-125.

34. Windsor DP. Variation between ejaculates in the fertility of frozen ram semen used for cervical insemination of Merino ewes. Anim Reprod Sci. 1997;47: 21-29.

35. Graham JK. Effect of seminal plasma on the motility of epididymal and ejaculated spermatozoa of the ram and bull during the cryopreservation process. Theriogenology. 1994;41:1151-1162.

36. Killian GJ, Chapman DA, Rogowski LE. Fertilityassociated proteins in Holstein bull seminal plasma. Biol Reprod. 1993;49:1202-1207.

37. Mortimer ST, Maxwell WMC. Effect of medium on the kinematics of frozen-thawed ram spermatozoa. Reproduction 2004; 127:285-291.

38. Ashworth PJC, Harrison RAP, Miller NGA, Plummer JM, Watson PF. Survival of ram spermatozoa at high 
dilution: protective effect of simple constituents of culture media as compared with seminal plasma. Reprod Fertil Dev. 1994;6:173-180.

39. Maxwell WMC, Welch GR, Johnson LA, Viability and membrane integrity of spermatozoa after dilution and flow cytometric sorting in the presence or absence of seminal plasma. Reprod Fertil Dev. 1997;8:1165-1178.

40. Barrios B, Pérez-Pé R, Gallego M, Tato A, Osada J, Muiño-Blanco T, Cebrián-Pérez JA. Seminal plasma proteins revert the cold-shock damage on ram sperm membrane. Biol Reprod. 2000;63:1531-1537.

41. Pérez-Pé R, Cebrián-Pérez JA, Muiño-Blanco T. Semen plasma proteins prevent cold-shock membrane damage to ram spermatozoa. Theriogenology. 2001;56:425-434.

42. Manjunath P, Nauc V, Bergeran A, Menard M. Major proteins of bovine seminal plasma bind to the low-density lipoprotein fraction of hen's egg yolk. Biol Reprod., 2002;67:1250-1258.

Protocolado em: 02 jan. 2014. Aceito em: 11 jun. 2014 